\title{
CYP19A1 polymorphisms associated with coronary artery disease and circulating sex hormone levels in a Chinese population
}

\author{
Yajie Meng ${ }^{1,2, *}$, Dilare Adi ${ }^{1,2, *}$, Yun Wu ${ }^{1,2}$, Yongtao Wang ${ }^{1,2}$, Mayila Abudoukelimu ${ }^{1,2}$, \\ Ding Huang ${ }^{1}$, Xiang Ma ${ }^{1,2}$, Cheng Liu ${ }^{1,2}$, Ting Wang ${ }^{1,2}$, Fen Liu ${ }^{1,2}$, Bangdang Chen ${ }^{1,2}$, \\ Mintao Gai ${ }^{1,2}$, Xiaocui Chen ${ }^{1,2}$, Zhenyan Fu' ${ }^{1,2}$ and Yitong $\mathrm{Ma}^{1,2}$ \\ ${ }^{1}$ Department of Cardiology, First Affiliated Hospital of Xinjiang Medical University, Urumqi, P.R. China \\ ${ }^{2}$ Xinjiang Key Laboratory of Cardiovascular Disease Research, Urumqi, P.R. China \\ *These authors contributed equally to this work
}

Correspondence to: Zhenyan Fu, email: fuzhenyan316@126.com Yitong Ma, email: myt-xj@163.com

Keywords: CYP19A1, coronary artery disease, sex hormone, polymorphisms

Abbreviations: $C A D=$ Coronary artery disease; SNPS = Single-nucleotide polymorphisms; $E 2=17 \beta$-estradiol; $T=$ Testosterone; $A=$ Aromatase

Received: December 30, 2016

Accepted: September 20, 2017

Published: October 07, 2017

Copyright: Meng et al. This is an open-access article distributed under the terms of the Creative Commons Attribution License 3.0 (CC BY 3.0), which permits unrestricted use, distribution, and reproduction in any medium, provided the original author and source are credited.

\section{ABSTRACT}

Background: The relationship between CYP19A1 genetic polymorphisms and coronary artery disease (CAD) remains unclear. Thus, the aim of the present study was to investigate the association of CYP19A1 genetic polymorphisms with CAD in Han and Uygur populations and to characterize the association between the levels of sex hormones and aromatase with single-nucleotide polymorphisms (SNPs) in CYP19A1 genes in Chinese women.

Results: There were significant differences in the genotype distributions of rs2236722 and rs4646 between CAD patients and control subjects in the Uygur population. The rs4646 was found to be associated with CAD in the dominant model (CC vs. $C A+A A$ ) and the additive model (CA vs. CC + AA) (both $P \leq 0.001$ ). The difference remained statistically significant after multivariate adjustment $(O R=0.483,95 \% \mathrm{CI}$ : $0.338-0.690, P=0.000$; and $O R=1.844,95 \% C I: 1.300-2.617, P=0.001$, respectively). In normal Uygur postmenopausal women, there were significant differences in the genotype distributions of rs4646 and the circulating hormone and aromatase levels between CAD patients and control subjects. The differences in estradiol and aromatase levels remained statistically significant after multivariate adjustment $(O R=0.889$, 95\% CI: 0.817-0.969, $P=0.007$; and OR $=0.947,95 \%$ CI: $0.936-0.957, P=0.000$, respectively). Additionally, there were differences in sex hormone levels between the different ethnicities among the Xinjiang Chinese population.

Materials and Methods: Among a total of 1,064 Han individuals (614 men and 450 women) and 790 Uygur individuals (484 men and 306 women), 498 postmenopausal women ( 265 Han and 233 Uygur individuals) were selected. Four SNPs (rs2236722, rs2304463, rs4646, and rs4275794) were genotyped using the improved multiplex ligation detection reaction (iMLDR) technique. The estradiol and testosterone levels were determined using a radioimmunoassay based on GC-2016y. In addition, an enzyme-linked immunosorbent assay (ELISA) was performed to determine the serum P450 aromatase levels.

Conclusions: The results of this study indicate that the rs2236722 and rs4646 of the CYP19A1 gene are associated with CAD and circulating sex hormone levels in the Xinjiang population of China. 


\section{INTRODUCTION}

Coronary artery disease (CAD) is a complex multifactorial cardiovascular disease that is influenced by both genetics and environmental risk factors. CAD is considered a major cause of mortality worldwide, and the incidence of coronary events in women is increasing, with most events occurring after the onset of menopause [1-2]. Previous studies have suggested that estrogen reduction is an important factor in the increased incidence of coronary heart disease among postmenopausal women [3]. There is also evidence that sex hormones influence the risk of developing $\mathrm{CAD}$, suggesting that declining levels of endogenous estrogen with age, the higher prevalence of obesity, and altered body fat distribution result in a proatherogenic metabolic environment and the subsequent development of significant vascular endothelial dysfunction [4-5].

In the estrogen pathway, the cytochrome P450 aromatase gene (CYP19A1) encodes a key enzyme involved in the conversion of androstenedione and testosterone to estrone (E1) and 17 $\beta$-estradiol (E2), respectively (Figure 1). Many studies have examined whether genetic variations in CYP19A1 are associated with cardiovascular diseases [6-8]. However, despite these efforts, the potential molecular mechanisms linking estrogen-related genes with $\mathrm{CAD}$ risk remain incompletely understood.

Herein, we present a case-control study designed to assess the association between the levels of sex hormones (total testosterone and estradiol) and P450 aromatase levels based on single-nucleotide polymorphisms (SNPs) in the CYP19A1 gene to investigate the relationship between CYP19A1 and CAD in the Chinese population. Moreover, we analyzed the correlations among aromatase, total testosterone, and estradiol.

\section{RESULTS}

\section{Characteristics of the study participants and frequencies of the SNPs}

The present study evaluated two ethnic groups $(1,046$ Han and 790 Uygur subjects). The clinical and metabolic characteristics of the study populations are shown separately for Han and Uygur participants in Tables 1 and 2 .

Tables 3 and 4 show the distribution of the CYP19A1 genotypes among the Han and Uygur populations. The genotype and allele distributions among the Han and Uygur patients and control participants for each SNP were consistent with the predicted HardyWeinberg equilibrium values (data not shown).

Table 3 shows that among the total Han population and male Han subjects, all SNP genotypes were not significantly different between CAD patients and control subjects $(P>0.05)$ in the dominant, recessive, and additive models. However, for female subjects, the SNP1 (rs2236722) and SNP3 (rs4646) genotypes in the dominant model (CC vs. CA + AA) were significant different between the CAD patients and control subjects ( $P=0.01$ and $P=0.05$, respectively).

Table 4 shows that in the Uygur population, two loci, SNP1 (rs2236722) and SNP3 (rs4646), were significantly associated with CAD. The distribution of the SNP1 genotypes was significantly different between CAD and control subjects (total: $P=0.003$, men: $P=0.04$ ). Additionally, the distribution of the rs4646 genotypes in the dominant model $(\mathrm{CC}$ vs. $\mathrm{CA}+\mathrm{AA})$ and additive model $(\mathrm{CA}$ vs. $\mathrm{CC}+\mathrm{AA})$ was significantly different between CAD and control subjects $(P=0.001, P=0.000$, and $P=0.001$, respectively). Similar to the men, the differences among women remained statistically significant. However, there was no significant difference between $\mathrm{CAD}$ and control subjects regarding the recessive model (AA vs. CC $+\mathrm{CA})(P=0.668)$. Among men, the distribution of the SNP2 genotypes in the dominant model $(\mathrm{CA}+\mathrm{AA}$ vs. $\mathrm{CC})$ was significantly different between the CAD and control subjects $(P=0.009$ and $P=0.004$, respectively). However, the SNP4 genotypes were not significantly different between CAD patients and control subjects (both $P>0.05$ ) in the dominant, recessive, and additive models.

\section{Logistic regression analyses}

Associations of the CYP19A1 rs2236722 and rs10046 polymorphisms with the traditional risk factors of CAD were observed. In the Uygur population, a multivariable logistic regression analysis was performed, combining the genotypes with the following variables: age, gender, hypertension, diabetes, smoking, drinking, BMI, TG, and LDL-C. After multivariate adjustment, SNP1 (rs2236722) remained significantly associated with $\mathrm{CAD}$ in terms of genotype $(\mathrm{OR}=0.271,95 \% \mathrm{CI}$ : $0.077-0.953, P=0.042)$. After multivariate adjustment, SNP3 (rs4646) remained significantly associated with $\mathrm{CAD}$ in the dominant model (CC vs. CA + AA) (total: OR $=0.483$, 95\% CI: $0.338-0.690, P=0.000$; and men: OR $=0.455,95 \%$ CI: $0.293-0.704, P=0.000)$ and the additive model (CA vs. $\mathrm{CC}+\mathrm{AA}$ ) (total: $\mathrm{OR}=1.844$, 95\% CI: $1.300-2.617, P=0.001$; men: $\mathrm{OR}=1.651,95 \%$ CI: $1.087-2.507, P=0.019$; and women: $\mathrm{OR}=2.179$, 95\% CI: $1.103-4.305, P=0.025)$, as shown in Table 5. In the Han population, because there was no difference in genotype distribution, further multivariable logistic regression analyses were not performed.

\section{SNPs and circulating sex hormone levels}

We analyzed the association of four SNPs in the CYP19A1 gene with circulating hormone and aromatase 
Table 1: Characteristics of the subjects (Han Chinese population)

\begin{tabular}{|c|c|c|c|c|c|c|c|c|c|}
\hline & \multicolumn{3}{|c|}{ Total } & \multicolumn{3}{|c|}{ Men } & \multicolumn{3}{|c|}{ Women } \\
\hline & CAD & Controls & $P$ & CAD & Controls & $P$ & CAD & Controls & $P$ \\
\hline Number $(n)$ & 611 & 453 & & 421 & 193 & & 190 & 260 & \\
\hline Age, mean (SD) & $59.65 \pm 11.12$ & $59.0 \pm 9.55$ & 0.134 & $59.10 \pm 11.71$ & $59.0 \pm 9.3$ & 0.284 & $60.32 \pm 8.24$ & $58.22 \pm 9.71$ & 0.169 \\
\hline EH $(\%)$ & $336(55)$ & $180(39.7)$ & 0.000 & $223(53)$ & $80(41.5)$ & 0.008 & $113(59.5)$ & $100(38.5)$ & 0.000 \\
\hline Diabetes (\%) & $155(25.4)$ & $46(10.2)$ & 0.000 & 105 (24.9) & $35(18.1)$ & 0.062 & $50(26.3)$ & $11(4.2)$ & 0.000 \\
\hline Smoking (\%) & $282(46.2)$ & $134(29.6)$ & 0.000 & $277(68.8)$ & $127(65.8)$ & 0.999 & $5(2.6)$ & $7(2.7)$ & 0.968 \\
\hline Drinking (\%) & $309(50.6)$ & $105(23.2)$ & 0.000 & $254(60.3)$ & $96(49.7)$ & 0.014 & $55(28.9)$ & $9(3.5)$ & 0.000 \\
\hline BMI, mean (SD) & $25.85 \pm 3.35$ & $24.49 \pm 3.29$ & 0.000 & $26.1 \pm 3.39$ & $25.48 \pm 3.04$ & 0.026 & $25.28 \pm 3.29$ & $23.77 \pm 3.29$ & 0.000 \\
\hline Glu (mmol/L) & $6.36 \pm 2.16$ & $5.51 \pm 1.89$ & 0.000 & $6.31 \pm 2.7$ & $6.05 \pm 2.49$ & 0.257 & $6.45 \pm 3.5$ & $5.11 \pm 1.30$ & 0.000 \\
\hline $\mathrm{TG}(\mathrm{mmol} / \mathrm{L})$ & $2.11 \pm 1.62$ & $1.75 \pm 1.48$ & 0.000 & $2.20 \pm 1.78$ & $2.25 \pm 1.85$ & 0.753 & $1.92 \pm 1.21$ & $1.37 \pm 0.98$ & 0.000 \\
\hline $\mathrm{TC}(\mathrm{mmol} / \mathrm{L})$ & $4.65 \pm 1.11$ & $4.38 \pm 2.87$ & 0.037 & $4.23 \pm 1.30$ & $4.86 \pm 1.18$ & 0.000 & $4.69 \pm 2.54$ & $4.48 \pm 1.02$ & 0.230 \\
\hline $\mathrm{HDL}(\mathrm{mmol} / \mathrm{L})$ & $1.12 \pm 0.84$ & $1.28 \pm 0.55$ & 0.010 & $1.06 \pm 0.83$ & $1.25 \pm 0.54$ & 0.001 & $1.25 \pm 0.84$ & $1.31 \pm 0.56$ & 0.466 \\
\hline $\mathrm{LDL}(\mathrm{mmol} / \mathrm{L})$ & $3.06 \pm 1.33$ & $2.58 \pm 1.11$ & 0.000 & $3.04 \pm 1.31$ & $2.46 \pm 1.03$ & 0.000 & $3.07 \pm 1.34$ & $2.82 \pm 1.24$ & 0.049 \\
\hline $\mathrm{UA}(\mu \mathrm{mol} / \mathrm{L})$ & $325.54 \pm 147.62$ & $290.90 \pm 83.95$ & 0.000 & $347.08 \pm 161.55$ & $331.17 \pm 85.48$ & 0.199 & $277.8 \pm 94.97$ & $261.01 \pm 69.12$ & 0.031 \\
\hline $\mathrm{Cr}(\mu \mathrm{mol} / \mathrm{L})$ & $77.51 \pm 35.36$ & $76.48 \pm 22.72$ & 0.580 & $82.82 \pm 38.44$ & $90.98 \pm 19.49$ & 0.006 & $65.73 \pm 23.46$ & $65.72 \pm 18.62$ & 0.996 \\
\hline BUN (mmol/L) & $6.26 \pm 7.59$ & $4.83 \pm 1.42$ & 0.000 & $6.44 \pm 7.92$ & $5.17 \pm 1.46$ & 0.002 & $5.86 \pm 6.79$ & $4.58 \pm 1.33$ & 0.003 \\
\hline
\end{tabular}

Continuous variables are expressed as the mean \pm SD. Categorical variables are expressed as percentages.

BMI, body mass index; BUN, blood urea nitrogen; Cr, creatinine; DM, diabetes mellitus; Glu, glucose; TG, triglyceride; TC, total cholesterol;

HDL, high-density lipoprotein; LDL, low-density lipoprotein; and UA, uric acid.

The $P$-value of the continuous variables was calculated using the independent-sample $t$-test. The $P$-value of the categorical variables was calculated by Fisher's exact test.

Table 2: Characteristics of subjects (Uygur Chinese population)

\begin{tabular}{|c|c|c|c|c|c|c|c|c|c|}
\hline & \multicolumn{3}{|c|}{ Total } & \multicolumn{3}{|c|}{ Men } & \multicolumn{3}{|c|}{ Women } \\
\hline & CAD & Controls & $P$ & CAD & Controls & $P$ & CAD & Controls & $P$ \\
\hline Number $(n)$ & 403 & 387 & & 316 & 168 & & 87 & 219 & \\
\hline Age, mean (SD) & $55.66 \pm 9.85$ & $52.85 \pm 8.55$ & 0.342 & $54.87 \pm 8.09$ & $52.26 \pm 8.16$ & 0.581 & $59 \pm 8.17$ & $53.31 \pm 8.8$ & 0.867 \\
\hline EH (\%) & $217(53.8)$ & $172(44.4)$ & 0.008 & $164(51.90)$ & $75(44.60)$ & 0.129 & $53(60.9)$ & $97(44.3)$ & 0.090 \\
\hline Diabetes (\%) & $90(23.3)$ & $31(8.1)$ & 0.000 & $64(21)$ & $14(8.5)$ & 0.001 & $26(31.7)$ & $17(7.8)$ & 0.000 \\
\hline Smoking (\%) & $174(43.2)$ & $79(20.5)$ & 0.000 & $173(54.7)$ & $75(45.2)$ & 0.046 & $1(1.1)$ & $4(1.8)$ & 0.673 \\
\hline Drinking (\%) & $173(42.9)$ & $34(8.8)$ & 0.000 & $147(46.5)$ & $34(20.2)$ & 0.000 & $26(29.9)$ & $0(0)$ & 0.000 \\
\hline BMI, mean (SD) & $27.11 \pm 3.78$ & $26.36 \pm 4.45$ & 0.011 & $27.04 \pm 3.68$ & $26.33 \pm 4.21$ & 0.540 & $27.35 \pm 4.12$ & $26.37 \pm 4.64$ & 0.089 \\
\hline Glu (mmol/L) & $6.08 \pm 2.49$ & $5.12 \pm 1.89$ & 0.000 & $5.88 \pm 2.15$ & $5.11 \pm 1.70$ & 0.000 & $6.83 \pm 3.37$ & $5.11 \pm 2.02$ & 0.000 \\
\hline $\mathrm{TG}(\mathrm{mmol} / \mathrm{L})$ & $2.04 \pm 1.34$ & $1.63 \pm 1.11$ & 0.000 & $1.96 \pm 1.30$ & $1.63 \pm 1.09$ & 0.070 & $2.34 \pm 1.42$ & $1.67 \pm 1.13$ & 0.000 \\
\hline $\mathrm{TC}(\mathrm{mmol} / \mathrm{L})$ & $4.67 \pm 3.01$ & $4.43 \pm 1.09$ & 0.147 & $4.56 \pm 2.48$ & $4.30 \pm 1.08$ & 0.213 & $5.08 \pm 4.40$ & $4.53 \pm 1.09$ & 0.034 \\
\hline $\mathrm{HDL}(\mathrm{mmol} / \mathrm{L})$ & $0.99 \pm 0.9$ & $1.21 \pm 0.45$ & 0.000 & $0.94 \pm 0.83$ & $1.24 \pm 0.46$ & 0.000 & $1.11 \pm 1.09$ & $1.19 \pm 0.44$ & 0.534 \\
\hline $\mathrm{LDL}(\mathrm{mmol} / \mathrm{L})$ & $2.72 \pm 1.40$ & $2.67 \pm 1.41$ & 0.656 & $2.69 \pm 1.45$ & $2.73 \pm 1.42$ & 0.727 & $2.86 \pm 1.18$ & $2.63 \pm 1.42$ & 0.169 \\
\hline $\mathrm{UA}(\mu \mathrm{mol} / \mathrm{L})$ & $313.86 \pm 99.99$ & $252.38 \pm 79.78$ & 0.000 & $323.81 \pm 92.36$ & $278.96 \pm 81.80$ & 0.000 & $276.8 \pm 117.79$ & $232.16 \pm 72.07$ & 0.002 \\
\hline $\mathrm{Cr}(\mu \mathrm{mol} / \mathrm{L})$ & $81.70 \pm 37.29$ & $72.26 \pm 28.34$ & 0.000 & $83.30 \pm 34.93$ & $80.42 \pm 32.40$ & 0.383 & $75.58 \pm 44.92$ & $66.06 \pm 23.02$ & 0.075 \\
\hline BUN (mmol/L) & $6.14 \pm 7.19$ & $5.20 \pm 1.50$ & 0.013 & $5.9 \pm 5.75$ & $5.38 \pm 1.52$ & 0.248 & $7.02 \pm 1.09$ & $5.06 \pm 1.47$ & 0.122 \\
\hline
\end{tabular}

Continuous variables are expressed as the mean $\pm \mathrm{SD}$. Categorical variables are expressed as percentages.

BMI, body mass index; BUN, blood urea nitrogen; Cr, creatinine; DM, diabetes mellitus; Glu, glucose; TG, triglyceride; TC, total cholesterol;

HDL, high-density lipoprotein; LDL, lo-density lipoprotein; and UA, uric acid.

The $P$-value of the continuous variables was calculated by the independent-sample $t$-test. The $P$-value of the categorical variables was calculated by Fisher's exact test. 
Table 3: Genotype and allele distributions among Han patients with CAD and control participants

\begin{tabular}{|c|c|c|c|c|c|c|c|c|c|c|}
\hline & & \multicolumn{3}{|c|}{ Total } & \multicolumn{3}{|c|}{ Men } & \multicolumn{3}{|c|}{ Women } \\
\hline & & $\begin{array}{c}\text { CAD } \\
n(\%)\end{array}$ & $\begin{array}{c}\text { Controls } \\
n(\%)\end{array}$ & $P$ & $\begin{array}{c}\text { CAD } \\
n(\%)\end{array}$ & $\begin{array}{c}\text { Controls } \\
n(\%)\end{array}$ & $\boldsymbol{P}$ & $\begin{array}{c}\text { CAD } \\
n(\%)\end{array}$ & $\begin{array}{c}\text { Controls } \\
n(\%)\end{array}$ & $\boldsymbol{P}$ \\
\hline \multirow{3}{*}{$\begin{array}{c}\text { SNP1 } \\
\text { rs2236722 } \\
\text { genotype }\end{array}$} & AA & $592(96.9)$ & $434(95.8)$ & \multirow{3}{*}{0.379} & $400(96)$ & 189 (97.9) & \multirow{3}{*}{0.422} & $188(98.9)$ & $245(94.2)$ & \multirow{3}{*}{0.01} \\
\hline & GA & $18(2.9)$ & $19(4.2)$ & & $16(3.8)$ & $4(2.1)$ & & $2(1.1)$ & $15(5.8)$ & \\
\hline & GG & $1(0.2)$ & $0(0)$ & & $1(0.2)$ & $0(0)$ & & $0(0)$ & $0(0)$ & \\
\hline \multirow{2}{*}{ Dominant model } & $\mathrm{AA}$ & 592 (96.9) & $434(95.8)$ & \multirow{2}{*}{0.346} & $400(96)$ & 189 (97.9) & \multirow{2}{*}{0.213} & & & \\
\hline & $\mathrm{GA}+\mathrm{GG}$ & $19(3.1)$ & $19(4.2)$ & & $17(4)$ & $4(2.1)$ & & & & \\
\hline \multirow{2}{*}{ Recessive model } & GG & $1(0.2)$ & $0(0)$ & \multirow{2}{*}{0.389} & $1(0.2)$ & $0(0)$ & \multirow{2}{*}{0.498} & & & \\
\hline & $\mathrm{AA}+\mathrm{GA}$ & $610(99.8)$ & $453(100)$ & & $420(99.8)$ & $193(100)$ & & & & \\
\hline \multirow{2}{*}{ Additive model } & GA & $18(2.9)$ & $19(4.2)$ & \multirow{2}{*}{0.272} & $16(3.8)$ & $4(2.1)$ & \multirow{2}{*}{0.263} & & & \\
\hline & $\mathrm{AA}+\mathrm{GG}$ & $593(97.1)$ & $434(95.8)$ & & $405(96.2)$ & 189 (97.9) & & & & \\
\hline \multirow{3}{*}{$\begin{array}{c}\text { SNP2 } \\
\text { rs2304463 } \\
\text { genotype }\end{array}$} & $\mathrm{CC}$ & 175 (28.6) & $123(27.2)$ & \multirow{3}{*}{0.408} & $132(31.4)$ & $60(31.1)$ & \multirow{3}{*}{0.998} & $43(22.6)$ & $63(24.2)$ & \multirow{3}{*}{0.124} \\
\hline & CA & $334(54.7)$ & $240(53)$ & & $215(51.1)$ & $99(51.3)$ & & $119(62.9)$ & $141(54.2)$ & \\
\hline & AA & $102(16.1)$ & $90(19.9)$ & & 74 (17.6) & 34 (17.6) & & $28(14.7)$ & $56(21.5)$ & \\
\hline \multirow{2}{*}{ Dominant model } & $\mathrm{CC}$ & 175 (28.6) & $123(27.2)$ & \multirow{2}{*}{0.593} & $132(31.4)$ & $60(31.1)$ & \multirow{2}{*}{0.947} & $43(22.6)$ & $63(24.2)$ & \multirow{2}{*}{0.693} \\
\hline & $\mathrm{CA}+\mathrm{AA}$ & $436(71.4)$ & $330(72.8)$ & & $289(68.6)$ & $133(68.9)$ & & $147(77.4)$ & $197(75.8)$ & \\
\hline \multirow{2}{*}{ Recessive model } & AA & $102(16.1)$ & $90(19.9)$ & \multirow{2}{*}{0.183} & $74(17.6)$ & $34(17.6)$ & & $28(14.7)$ & $56(21.5)$ & \\
\hline & $\mathrm{CC}+\mathrm{CA}$ & $509(83.3)$ & $363(80.1)$ & & $347(82.4)$ & $159(82.4)$ & (0.0 & $162(85.3)$ & $204(78.5)$ & 8.001 \\
\hline & $\mathrm{CA}$ & $334(54.7)$ & $240(53)$ & & $215(51.1)$ & $99(51.3)$ & & $119(62.9)$ & $141(54.2)$ & \\
\hline 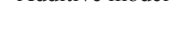 & $\mathrm{CC}+\mathrm{AA}$ & $277(45.3)$ & $213(47.0)$ & & $99(51.3)$ & 94 (48.7) & & $71(37.4)$ & $119(45.8)$ & \\
\hline & $\mathrm{CC}$ & 354 (57.9) & $243(53.6)$ & & $232(55.1)$ & $100(51.8)$ & & $122(64.2)$ & $143(55)$ & \\
\hline rs4646 & $\mathrm{CA}$ & $212(34.7)$ & $173(38.2)$ & 0.377 & $157(37.3)$ & $80(41.5)$ & 0.608 & 55 (28.9) & $93(35.8)$ & 0.143 \\
\hline & AA & $45(7.4)$ & $37(8.2)$ & & $32(7.6)$ & $13(6.7)$ & & $13(6.8)$ & $74(9.2)$ & \\
\hline & $\mathrm{CC}$ & 354 (57.9) & $243(53.6)$ & & $232(55.1)$ & $100(51.8)$ & & $122(64.2)$ & $143(55)$ & \\
\hline 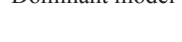 & $\mathrm{CA}+\mathrm{AA}$ & $257(42.1)$ & $210(46.4)$ & 0.100 & $189(44.9)$ & $93(48.2)$ & $0.4+7$ & $68(35.8)$ & $117(45)$ & 0.03 \\
\hline & AA & $45(7.4)$ & $37(8.2)$ & & $32(7.6)$ & $13(6.7)$ & & $13(6.8)$ & $74(9.2)$ & \\
\hline Recessive model & $\mathrm{CC}+\mathrm{CA}$ & $566(92.6)$ & $416(91.8)$ & 0.021 & $389(92.4)$ & $180(93.3)$ & 0.103 & $177(93.2)$ & $236(90.8)$ & 0.362 \\
\hline & $\mathrm{CA}$ & $212(34.7)$ & $173(38.2)$ & & $157(37.3)$ & $80(41.5)$ & & $55(28.9)$ & $93(35.8)$ & \\
\hline Additive model & $\mathrm{CC}+\mathrm{AA}$ & $399(65.3)$ & $280(61.87)$ & 0.241 & $264(62.7)$ & $113(58.5)$ & 0.326 & $135(71.7)$ & $167(64.2)$ & 0.128 \\
\hline SNP4 & $\mathrm{TT}$ & 415 (67.9) & $307(67.8)$ & & $279(66.3)$ & $129(66.8)$ & & $136(71.6)$ & $178(68.5)$ & \\
\hline rs4275794 & CT & $179(29.3)$ & $132(29.1)$ & 0.975 & $128(30.4)$ & $57(29.5)$ & 0.963 & $51(26.8)$ & $75(28.8)$ & 0.63 \\
\hline genotype & $\mathrm{CC}$ & $17(2.8)$ & $14(3.1)$ & & $14(3.3)$ & $7(3.6)$ & & $3(1.6)$ & $7(2.7)$ & \\
\hline & TT & 415 (67.9) & $307(67.8)$ & & $279(66.3)$ & $129(66.8)$ & & $136(71.6)$ & $178(68.5)$ & \\
\hline Dommant moder & $\mathrm{CT}+\mathrm{CC}$ & $196(32.1)$ & $146(32.2)$ & 0.905 & $142(33.7)$ & $64(33.2)$ & 0.09 & $54(28.4)$ & $82(31.5)$ & $0.4 / 1$ \\
\hline & $\mathrm{CC}$ & $17(2.8)$ & $14(3.1)$ & & $14(3.3)$ & $7(3.6)$ & & $3(1.6)$ & $7(2.7)$ & \\
\hline Kecessive moder & $\mathrm{TT}+\mathrm{CT}$ & $594(97.2)$ & 439 (96.9) & 0.173 & 407 (96.7) & $186(96.4)$ & 0.049 & 187 (98.4) & $253(97.3)$ & 0.429 \\
\hline
\end{tabular}


CAD, Coronary artery disease; n, number of participants; and SNP, single-nucleotide polymorphism.

The $P$-value of the genotypes was calculated by Fisher's exact test; " $P<0.05$.

levels in normal postmenopausal women. Statistically significant associations with hormone levels were observed in the two ethnic groups.

Supplementary Table 1 shows that in the Uygur CAD population, SNP3(rs4646) is significantly associated with differences in estradiol, testosterone, and aromatase levels ( $P=0.040, P=0.007$, and $P=0.009$, respectively), and this association remained significant after adjustments for age, BMI, BUN, and glucose levels $(P=0.05$, $P=0.03$, and $P=0.03$, respectively). In the Uygur control population, SNP3 was significantly associated with differences in all circulating hormone and aromatase levels $(P=0.000$ and $P=0.007$, respectively), and the association remained significant after adjustments for age, BMI, BUN, and glucose levels $(P=0.000$ and $P=0.026$, respectively). In the Han CAD population (data not shown), rs4646 was associated with differences in testosterone and aromatase levels $(P=0.003$ and
$P=0.007$, respectively). However, the association was not statistically significant after adjustment. In the control Han population, this SNP at rs4646 was associated only with differences in estradiol levels $(P=0.009)$, and the adjusted model remained significant $(P=0.034)$. Several loci were not related to hormone levels and CAD (both $P>0.05$ ).

Table 6 shows the results of a multivariable logistic regression analysis combining hormone levels and aromatase levels with the following variables: rs4646 (CC); the incidence of diabetes and hypertension; age; nation(Han and Uygur); and BMI, which are major confounding factors of CAD. After multivariate adjustment, CAD remained significantly associated with estradiol $(\mathrm{OR}=0.889,95 \%$ CI:0.817-0.969, $P=0.007)$ and aromatase $(\mathrm{OR}=0.947$, 95\% CI:0.936-0.957, $P=0.000$ ) but not testosterone (OR $=6.894,95 \% \mathrm{CI}: 0.876-4.967, P=0.067$ ).

In both the Uygur and Han populations, estrogen levels were higher in the control group than in the case

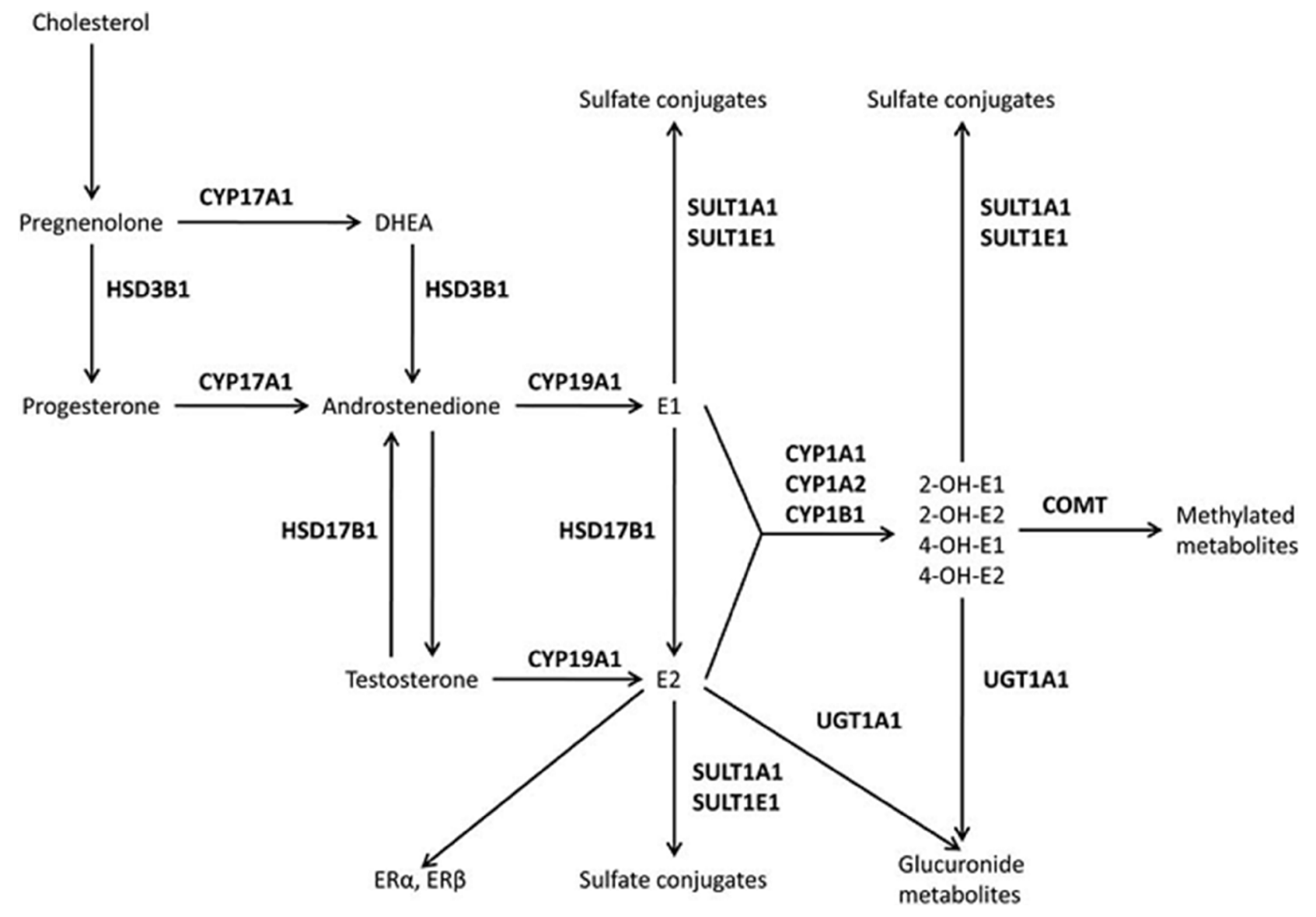

Figure 1: The estrogen pathway. Hydroxysteroid dehydrogenases (HSD3B1 and HSD17B1), cytochrome P450 (CYP1A1, CYP1A2, CYP17A1, CYP19A1, and CYP1B1), catechol-O-methyltransferase (COMT), uridine diphospho-glucuronosyltransferase (UGT1A1), sulfotransferases (SULT1A1 and SULT1E1), and estrogen receptors (ER) alpha and beta. 


\begin{tabular}{|c|c|c|c|c|c|c|c|c|c|c|}
\hline & & \multicolumn{3}{|c|}{ Total } & \multicolumn{3}{|c|}{ Men } & \multicolumn{3}{|c|}{ Women } \\
\hline & & $\begin{array}{l}\text { CAD } \\
n(\%)\end{array}$ & $\begin{array}{c}\text { Controls } \\
n(\%)\end{array}$ & $P$ & $\begin{array}{l}\text { CAD } \\
n(\%)\end{array}$ & $\begin{array}{c}\text { Controls } n \\
(\%)\end{array}$ & $P$ & $\begin{array}{c}\text { CAD } \\
n(\%)\end{array}$ & $\begin{array}{c}\text { Controls } \\
n(\%)\end{array}$ & $P$ \\
\hline \multirow{2}{*}{$\begin{array}{c}\text { SNP1 } \\
\text { rs2236722 } \\
\text { genotype }\end{array}$} & $\mathrm{AA}$ & $399(99)$ & $370(95.6)$ & \multirow{2}{*}{0.03} & $314(99.4)$ & $163(97)$ & \multirow{2}{*}{0.04} & 85 (97.7) & $207(96.7)$ & \multirow{2}{*}{0.653} \\
\hline & GA & $4(1)$ & $17(4.4)$ & & $2(0.6)$ & $5(3)$ & & $2(2.3)$ & $7(3.3)$ & \\
\hline \multirow{3}{*}{$\begin{array}{c}\text { SNP2 } \\
\text { rs2304463 } \\
\text { genotype }\end{array}$} & $\mathrm{CC}$ & $108(26.8)$ & $87(22.5)$ & \multirow{3}{*}{0.365} & $86(27.2)$ & $26(15.5)$ & \multirow{3}{*}{0.009} & $22(25.3)$ & $61(27.9)$ & \multirow{3}{*}{0.589} \\
\hline & $\mathrm{CA}$ & $191(47.4)$ & $192(49.6)$ & & $152(48.1)$ & $87(51.8)$ & & $39(44.8)$ & $105(47.9)$ & \\
\hline & AA & $104(25.8)$ & $108(27.9)$ & & $78(24.7)$ & $55(32.7)$ & & $26(29.9)$ & $53(24.2)$ & \\
\hline \multirow{2}{*}{$\begin{array}{l}\text { Dominant } \\
\text { model }\end{array}$} & $\mathrm{CC}$ & $108(26.8)$ & $87(22.5)$ & \multirow{2}{*}{0.159} & $86(27.2)$ & $26(15.5)$ & \multirow{2}{*}{0.004} & $22(25.3)$ & $61(27.9)$ & \multirow{2}{*}{0.649} \\
\hline & $\mathrm{CA}+\mathrm{AA}$ & $295(73.2)$ & $300(73.5)$ & & $230(72.8)$ & $142(84.5)$ & & $65(74.7)$ & $158(72.1)$ & \\
\hline \multirow{2}{*}{$\begin{array}{c}\text { Recessive } \\
\text { model }\end{array}$} & $\mathrm{AA}$ & $104(25.8)$ & $108(27.9)$ & \multirow{2}{*}{0.505} & $78(24.7)$ & $55(32.7)$ & \multirow{2}{*}{0.059} & $26(29.9)$ & $53(24.2)$ & \multirow{2}{*}{0.305} \\
\hline & $\mathrm{CC}+\mathrm{CA}$ & $299(74.2)$ & $279(22.1)$ & & $238(75.3)$ & $113(67.3)$ & & $61(70.1)$ & $166(75.8)$ & \\
\hline \multirow{2}{*}{$\begin{array}{l}\text { Additive } \\
\text { model }\end{array}$} & $\mathrm{CA}$ & $191(47.4)$ & $192(49.6)$ & \multirow{2}{*}{0.533} & $152(48.1)$ & $87(51.8)$ & \multirow{2}{*}{0.44} & $39(44.8)$ & 105 (47.9) & \multirow{2}{*}{0.622} \\
\hline & $\mathrm{CC}+\mathrm{AA}$ & $212(52.6)$ & $195(50.4)$ & & $164(51.9)$ & $81(48.2)$ & & $48(55.2)$ & $114(52.1)$ & \\
\hline \multirow{3}{*}{$\begin{array}{c}\text { SNP3 } \\
\text { rs4646 } \\
\text { genotype }\end{array}$} & $\mathrm{CC}$ & $172(42.7)$ & $210(54.3)$ & \multirow{3}{*}{0.001} & $140(44.3)$ & $90(53.6)$ & \multirow{3}{*}{0.007} & $32(36.8)$ & $120(54.8)$ & \multirow{3}{*}{0.017} \\
\hline & $\mathrm{CA}$ & $185(45.9)$ & $129(33.3)$ & & $143(45.3)$ & $52(31)$ & & $42(48.3)$ & 77 (35.2) & \\
\hline & AA & $46(11.4)$ & $48(12.4)$ & & $33(10.4)$ & $26(15.5)$ & & $13(14.9)$ & $22(10)$ & \\
\hline \multirow{2}{*}{$\begin{array}{c}\text { Dominant } \\
\text { model }\end{array}$} & $\mathrm{CC}$ & $172(42.7)$ & $210(54.3)$ & & $140(44.3)$ & $90(53.6)$ & & $32(36.8)$ & $120(54.8)$ & \\
\hline & $\mathrm{CA}+\mathrm{AA}$ & $231(57.3)$ & $177(45.7)$ & 0.000 & $176(55.7)$ & 78 (46.4) & 0.002 & $55(63.2)$ & $99(45.2)$ & 0.034 \\
\hline Recessive & $\mathrm{AA}$ & $46(11.4)$ & 48 (12.4) & $0<6$ & $33(10.4)$ & $26(15.5)$ & ${ }_{0}$ & $13(14.9)$ & $22(10)$ & \\
\hline model & $\mathrm{CC}+\mathrm{CA}$ & 357 (88.6) & $339(87.6)$ & & $283(89.6)$ & $142(84.5)$ & & $74(85.1)$ & $197(90)$ & \\
\hline Additive & $\mathrm{CA}$ & $185(45.9)$ & $129(33.3)$ & & $143(45.3)$ & $52(31)$ & & $42(48.3)$ & $77(35.2)$ & \\
\hline model & $\mathrm{CC}+\mathrm{AA}$ & $218(54.1)$ & $238(66.7)$ & & $173(54.7)$ & $116(69)$ & & $45(51.7)$ & $142(64.8)$ & \\
\hline SNP4 & TT & $278(69)$ & $263(68)$ & & $214(67.7)$ & $105(62.5)$ & & $64(73.6)$ & $158(72.1)$ & \\
\hline rs4275794 & $\mathrm{CT}$ & 109 (27) & $108(27.9)$ & 0.953 & $87(27.5)$ & $55(32.7)$ & 0.48 & $22(25.3)$ & $53(24.2)$ & 0.503 \\
\hline genotype & $\mathrm{CC}$ & $16(4)$ & $16(4.1)$ & & $15(4.7)$ & $8(4.8)$ & & $1(1.1)$ & $8(3.7)$ & \\
\hline Dominant & TT & $278(69)$ & $263(68)$ & & $214(67.7)$ & $105(62.5)$ & & $64(73.6)$ & $158(72.1)$ & \\
\hline model & $\mathrm{CT}+\mathrm{CC}$ & $125(31)$ & $124(32)$ & & $102(32.3)$ & $63(37.5)$ & & $23(26.4)$ & $61(27.9)$ & \\
\hline Recessive & $\mathrm{CC}$ & $16(4)$ & $16(4.1)$ & 7 & $15(4.7)$ & $8(4.8)$ & POP & $1(1.1)$ & $8(3.7)$ & \\
\hline model & $\mathrm{TT}+\mathrm{CT}$ & 387 (96) & 371 (95.9) & 0.907 & $301(95.3)$ & $160(95.2)$ & 0.994 & $86(98.9)$ & $211(96.3)$ & 0.242 \\
\hline Additive & $\mathrm{CT}$ & $109(27)$ & $108(27.9)$ & ( & $87(27.5)$ & $55(32.7)$ & (2) & $22(25.3)$ & $53(24.2)$ & 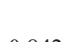 \\
\hline model & $\mathrm{TT}+\mathrm{CC}$ & $294(73)$ & $279(72.1)$ & & $229(72.5)$ & $113(67.3)$ & & $65(74.7)$ & $166(75.8)$ & \\
\hline
\end{tabular}

CAD, Coronary artery disease; n, number of participants; and SNP, single-nucleotide polymorphism.

The $P$-value of the genotypes was calculated by Fisher's exact test; $P<0.05$.

group. However, the testosterone levels were higher in the case group than in the control group, and the same phenomenon was observed for testosterone/estrogen levels. With respect to aromatase levels, the control group showed higher levels than the case group. Overall, the hormone levels in the Uygur population were lower than those in the Han population (Figures 2 and 3).

\section{DISCUSSION}

\section{Findings}

In the present study, we observed that variations in the CYP19A1 gene were associated with CAD in a Uygur population in China. We further examined the potential 
Table 5: Multiple logistic regression analysis for CAD patients and control subjects of the Uygur Chinese population

\begin{tabular}{|c|c|c|c|c|c|c|}
\hline & \multicolumn{2}{|l|}{ Total } & \multicolumn{2}{|l|}{ Men } & \multicolumn{2}{|c|}{ Women } \\
\hline & OR (95\% CI) & $P$ & OR (95\% CI) & $P$ & OR $(95 \%$ CI $)$ & $P$ \\
\hline $\begin{array}{c}\text { rs2236722 }(\mathrm{SNP} 1) \\
\text { genotype }\end{array}$ & $0.271(0.077-0.953)$ & 0.042 & $0.177(0.03-1.046)$ & 0.056 & $0.295(0.032-2.706)$ & 0.280 \\
\hline $\begin{array}{c}\text { rs4646 (SNP3) } \\
\text { Dominant model } \\
(\mathrm{CC} \text { vs. CA + AA })\end{array}$ & $0.483(0.338-0.690)$ & 0.000 & $0.455(0.293-0.704)$ & 0.000 & $0.585(0.301-1.138)$ & 0.114 \\
\hline $\begin{array}{c}\text { rs4646 (SNP3) } \\
\text { Additive model } \\
(\mathrm{CA} \text { vs. CC + AA) }\end{array}$ & $1.844(1.300-2.617)$ & 0.001 & $1.651(1.087-2.507)$ & 0.019 & $2.179(1.103-4.305)$ & 0.025 \\
\hline
\end{tabular}

OR, odds ratios; and 95\% CI, 95\% confidence intervals; $P<0.05$.

Table 6: Multiple logistic regression analysis of the association between female sex hormone and aromatase levels among normal Chinese postmenopausal female CAD patients and control subjects

\begin{tabular}{lcc}
\hline Factor & OR $(\mathbf{9 5 \%}$ CI) & $\boldsymbol{P}$ \\
\hline Estradiol $(\mathrm{pg} / \mathrm{ml})$ & $0.889(0.817-0.969)$ & 0.007 \\
Testosterone & $6.894(0.876-4.967)$ & 0.067 \\
Aromatase (IU/L) & $0.947(0.936-0.957)$ & 0.000 \\
rs4646 (CC) & $0.493(0.261-0.93)$ & 0.029 \\
Age & $1.047(1.005-1.091)$ & 0.027 \\
nation & $0.914(0.428-1.953)$ & 0.816 \\
BMI & $0.98(0.912-1.052)$ & 0.577 \\
EH & $1.229(0.665-2.271)$ & 0.511 \\
Diabetes & $3.253(1.409-7.511)$ & 0.006 \\
\hline
\end{tabular}

OR, odds ratios; and 95\% CI, 95\% confidence intervals; $P<0.05$.

associations between genotypes and the levels of sex hormones in postmenopausal Chinese women. The data indicated that SNP3 (rs4646) was strongly associated with estradiol, testosterone, and aromatase levels.

The human CYP19A1 gene is located on chromosome $15 \mathrm{q} 21.2$ and encodes an $\sim 130 \mathrm{~kb}$ sequence that includes nine (II-X) coding exons [9]. In postmenopausal women, a critical step in estrogen biosynthesis involves the formation of $\mathrm{C} 18$ estrogens (estrone and estradiol) from $\mathrm{C} 19$ androgens (androstenedione and testosterone). The aromatase gene CYP19A1 is critical for this transformation [10-11]. Previous studies have mainly focused on the relationship between polymorphisms in the CYP19A1 gene and breast cancer [12-15]. CYP19A1 is related to estrogen, and both animal experiments and clinical observations have demonstrated that the occurrence of $\mathrm{CAD}$ is related to the levels of sex hormones in the body [16-18]. Thus, estrogen likely plays a protective role in the cardiovascular system; therefore, it is not surprising that CYP19A1 polymorphisms are associated with CAD.

In this study, we recruited subjects from the ethnic minorities in Xinjiang, China, including Uygur and Han populations. We observed that polymorphisms in CYP19A1 were associated with CAD in the Uygur population. In the total and male populations, the frequency of GA genotypes for SNP1 (rs2236722) was higher in control subjects than in CAD subjects, and there were significant differences in the genotypes after multivariate adjustments for the confounding factors of $\mathrm{CAD}$, indicating that the GA genotype may be protective against CAD. Notably, SNP1 (rs2236722) is a missense mutation observed at 39 loci, in which Trp is changed to Arg in exon 2. The study of CYP19A1 gene function is ongoing. Using the SNP1 mutation, we have constructed a mutant plasmid and a wild-type plasmid, and cell and animal experiments continue to be carried out simultaneously; however, detailed results are not yet available. Nevertheless, these studies will greatly contribute to a better understanding of the CYP19A1 gene.

Because CYP19A1 directly affects estrogen levels, many scholars believe that polymorphisms of the CYP19A1 gene may affect the level of sex hormones in different individuals. Christopher A. Haiman [19] found 

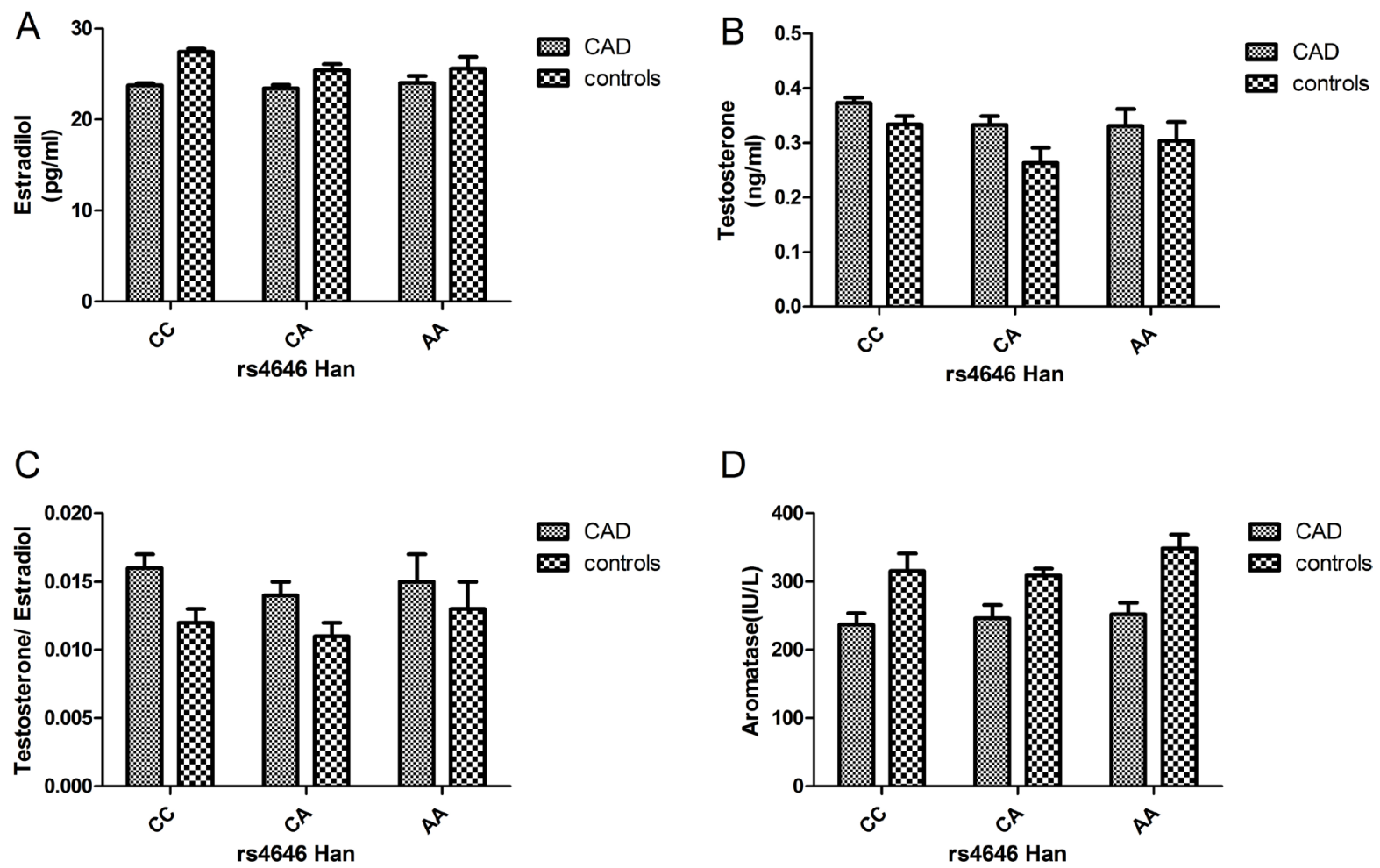

Figure 2: (A-D) Circulating sex hormone and aromatase levels (after adjustment; mean \pm SE) in Han postmenopausal female CAD and control subjects with each rs4646 genotype (CAD: CC: 111, CA: 47, and AA: 12; controls: CC: 50, CA: 15, and AA: 4).
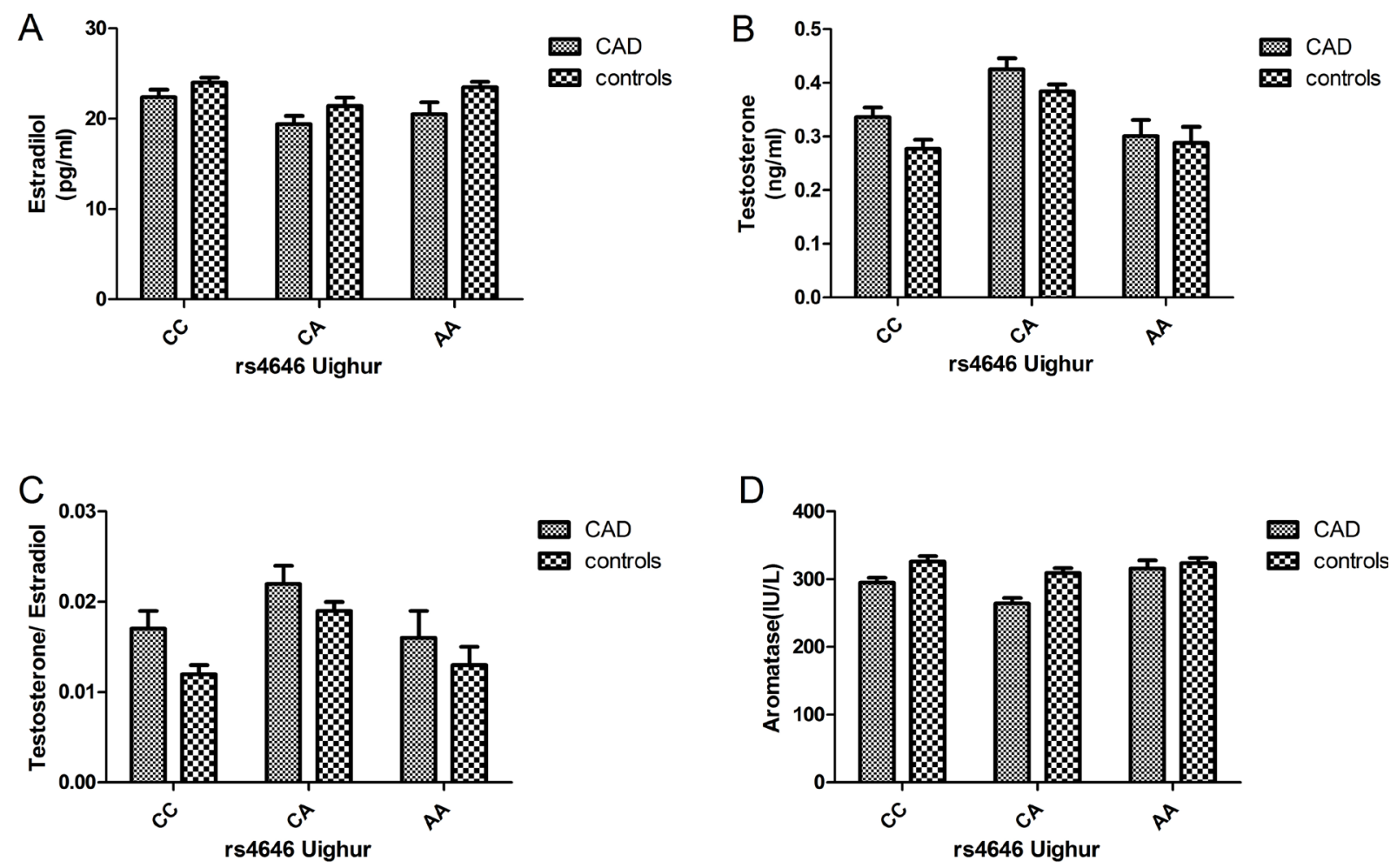

Figure 3: (A-D) Circulating sex hormone and aromatase levels (after adjustment; mean \pm SE) in Uygur postmenopausal female CAD and control subjects with each rs4646 genotype (CAD: CC: 32, CA: 26, and AA: 12; controls: CC: 47, CA: 76, and AA: 14). 
that 103 polymorphisms of CYP19 were in linkage disequilibrium European white women, and haplotype construction analysis showed that the CYP19 geneencoding region close to the $5^{\prime}$ non-encoding region was associated with significantly increased postmenopausal estrogen levels. In particular, the greater than $67 \mathrm{~kb}$ region, including the coding region, $3^{\prime} \mathrm{UTR}$, and tissue-specific promoters I.2, I.6, I.3 and PII, is associated with the conversion of androgens to estrogens. The Chinese scholar Hui Cai [20] studied postmenopausal women in China and found that an AA genotype near the I.4 promoter site in rs 1902584 was associated with low levels of estradiol in overweight and postmenopausal women. Additionally, the Japanese scholar Kumiko Kidokoro [21] identified 25 SNP loci in the CYP19 gene among 100 postmenopausal Japanese women and found that rs12148604 in the 3'UTR was weakly associated with estrone and testosterone levels.

In our research, we found that the frequency of the CA genotype for SNP3 (rs4646) was higher in CAD subjects than in control subjects and that there were significant differences among the genotypes in the additive models in the Uygur population. Moreover, this difference remained significant after multivariate adjustments for the confounding factors of $\mathrm{CAD}$, indicating that the $\mathrm{CA}$ genotype may be a risk factor for CAD. In contrast, the frequency of the CC genotype was higher in control subjects than in CAD subjects, and there were significant differences among the genotypes in the dominant models. After multivariate adjustments for the confounding factors of $\mathrm{CAD}$, the difference remained significant, indicating that the $\mathrm{CC}$ genotype may be protective against $\mathrm{CAD}$.

The results showed that sex hormones levels were significantly affected by SNP3 (rs4646) in the 3 'untranslated region (UTR). In CAD and control groups, the protective CC genotype of rs4646 was associated with higher estradiol and aromatase levels than the other two homozygous genotypes, but the testosterone level was lower in individuals with the CC genotype than the other two homozygous genotypes. There were also significant differences among different races; for example, the levels of estradiol and aromatase were higher among Uygur normal postmenopausal women than Han normal postmenopausal women. We further conducted multivariable logistic regression analyses combining hormone and aromatase levels with the rs4646 CC genotype and the major confounding factors of CAD. After multivariate adjustment, $\mathrm{CAD}$ remained significantly associated with estradiol $(\mathrm{OR}=0.889,95 \%$ CI:0.817-0.969, $P=0.007$ ) but not testosterone (OR $=6.894,95 \%$ CI:0.876-4.967, $P=0.067)$. CAD also remained significantly associated with aromatase after adjustments for confounders of CAD (OR $=0.947,95 \%$ CI:0.936-0.957, $P=0.000$ ).

Our findings are consistent with those of previous studies, showing that there is an association between polymorphisms in the $3^{\prime}$ UTR (rs10046) and sex hormone levels [22-23]. Notably, previous studies have also identified SNPs in the same 3' UTR. The HapMap database showed rs10046 in four ethnicities: JPT (Japanese individuals from Tokyo), HCB (Han Chinese individuals from Beijing), CEU (American individuals from Utah with northern and western European ancestry), and YRI (Yoruba individuals from Ibadan and Nigeria) [19-24]. Therefore, the results of the present study for SNP3 combined with those of other studies suggest that there is a functional region in the $3^{\prime}$ UTR of CYP19A1 and imply that its association with estradiol levels may reflect the presence of another polymorphism in the noncoding region that is in linkage disequilibrium with the SNPs in the 3' UTR and influence hormone levels among postmenopausal women of various ethnic backgrounds (two ethnic groups were included in the present study). At the same time, these SNPs may play a role in the occurrence and development of CAD. Therefore, a better understanding of the pathogenesis of coronary heart disease may help improve prognosis.

We found that aromatase and estrone levels are reduced and that testosterone levels are increased in postmenopausal women with CAD. This finding may indicate that in postmenopausal women, aromatase activity decreases with increasing testosterone levels and estrone levels are decreased compared with controls. Moreover, the appropriate proportion of testosterone/estrogen levels protects women, but when the levels are imbalanced, there may be a harmful effect [25]. Polycystic ovary syndrome (PCOS) has been hypothesized to be caused by functional ovarian hyperandrogenism $(\mathrm{FOH})$ resulting from dysregulated androgen secretion [26]. Indeed, women with multiple ovarian syndrome are at high risk for coronary heart disease [27]. Aromatase affects androgen levels in women after menopause because aromatase converts testosterone to estradiol. Studies have shown that the inhibition of aromatase activity can reduce the levels of estrogen, resulting in excessive accumulation of the androgen precursor [28]. In postmenopausal women, the prevalence of coronary heart disease is increased; however, whether increased androgen levels, gender imbalance, or decreased aromatase activity contribute to this effect requires further investigation. An increasing number of studies have tested the effects of genetic variations in the aromatase (CYP19A1) gene on CAD; however, whether the CYP19A1 gene is associated with CAD remains controversial.

Although the nature of our study is similar to previously published studies on CAD in other Han Chinese populations, this is the first study to investigate and compare CYP19A1 gene polymorphisms, sex hormones levels, and potential risk factors of CAD in different ethnicities in Xinjiang, northwestern part of China with a unique lifestyle and natural environment. Xinjiang is part of the ancient Silk Road and borders eight countries. 
There are more than 13 ethnic groups living in this area. The Uygur people account for $46 \%$ of the population, and the Han people account for $40 \%$. There is an important difference between the habits and diets of the two ethnic groups. In addition, the Uygur are an admixed population, originating from intermarriages between Caucasians and East Asians, thus contributing another important difference between the Uygur and Han populations.

\section{Limitations and shortcomings}

There are several limitations in the present study. First, the source of CAD patients was limited to the First Affiliate Hospital of Xinjiang Medical University, and these subjects may possess some risk factors of cardiovascular disease. Second, the relatively small sample size of this study may have contributed to weak statistical significance and wide CIs in the estimation of the OR. Third, there is a lack of individual genetic background information for the Uygur subjects. Finally, although we confirmed that CYP19A1 was associated with $\mathrm{CAD}$ and the levels of sex hormones and aromatase in postmenopausal Chinese women, we did not assess the polymorphic loci. Moreover, the present study lacked functional validation. However, assessments of the functional outcomes and correlations with hormonal levels are currently ongoing. Nevertheless, a prospective cohort study with a reasonably long study duration is required to obtain evidence with higher quality and reliability.

\section{MATERIALS AND METHODS}

\section{Ethics approval of the study protocol}

This study was approved by the Ethics Committee of the First Affiliated Hospital of Xinjiang Medical University (Xinjiang, China) and conducted according to the standards of the Declaration of Helsinki. Written informed consent was obtained from each participant, including explicit permission for DNA analysis and the collection of relevant clinical data.

\section{Study population}

We randomly recruited 611 Han (421 men and 190 women) and 403 Uygur (316 men and 87 women) patients with CAD as well as 453 Han and 387 Uygur individuals as ethnically and geographically matched control subjects. Among these individuals, 498 postmenopausal women (265 Han and 233 Uygur individuals) were selected from a subset of participants older than 55 years old who had not menstruated for 1 year or more and had not received hormone replacement therapy for at least 3 months prior to sampling. All subjects were inpatients of the First Affiliated Hospital of Xinjiang Medical University from 2013 to 2016. CAD was defined as the presence of at least one major coronary artery with stenosis affecting more than $50 \%$ of the luminal diameter on coronary angiography. Control subjects also underwent a coronary angiogram and were confirmed to be free of coronary artery stenosis; they also did not exhibit clinical or electrocardiographic evidence of myocardial infarction (MI) or CAD. However, some control subjects had cardiovascular risk factors, such as essential hypertension (EH), diabetes mellitus (DM), or hyperlipidemia, suggesting that the control group was exposed to the same risk factors of CAD, but the results of the coronary angiogram were normal. All information and data (including EH, DM, hyperlipidemia, and smoking) were collected from all study subjects, and these individuals were matched between two CAD and control cohorts. Patients were diagnosed with hypertension if they were on antihypertensive medication or if their systolic blood pressure (SBP) was $>140 \mathrm{~mm} \mathrm{Hg}$ or diastolic blood pressure (DBP) was $>90 \mathrm{~mm} \mathrm{Hg}$ in 3 measurements. DM was diagnosed according to the criteria of the American Diabetes Association [29]. Smoking status was dichotomized as smokers (current and ex-smokers) or nonsmokers. Additionally, all participants with impaired renal function, malignancies, connective tissue disease, chronic inflammatory disease, multiple organ failure, or mental disorders were excluded from the present study. All study participants provided written informed consent.

\section{Sex hormone analysis in normal postmenopausal women}

Sex hormone measurements were obtained using stored serum samples from the 498 postmenopausal women. After conducting comparative studies, which established that there were only minor differences between values obtained from the plasma and serum samples from the same individual, the remaining measurements were obtained from plasma samples. Sex hormone analyses were sequentially performed for estradiol and then testosterone using the available plasma or serum from each subject; $100 \%$ of the subjects had sufficient plasma or serum to complete the estradiol and testosterone measurements. Total testosterone and estradiol was measured using a radioimmunoassay kit (T*KIT-B10PZA and E2*KIT-B05PZA, Beijing North Institute of Biological Technology, Beijing, China) based on GC-2016 $\gamma$ using a radioimmunoassay counter at the Clinical Nuclear Medicine Department of the First Affiliated Hospital of Xinjiang Medical University. Total testosterone and estradiol precision was determined based on batch variation of $\mathrm{cv}<10 \%$, inter-batch variation of $\mathrm{cv}$ $<15 \%$, a concentration of $3.1 \mathrm{nmol} / \mathrm{L}$, and a sensitivity limit of $0.14 \mathrm{nmol} / \mathrm{L}$. Plasma P450 aromatase levels were measured using an enzyme-linked immunosorbent assay (Human Aromatase ELISA Kit, Beijing Kamal Shu Biotechnology Institute, Beijing, China). Absorbance (OD) was measured at $450 \mathrm{~nm}$ using a BIO-RAD xMark ${ }^{\mathrm{TM}}$ 
Microplate Spectrophotometer, and a standard curve was used to calculate the human aromatase concentration based on a batch variation of $\mathrm{cv}<9 \%$ and an inter-batch variation of $\mathrm{cv}<11 \%$.

\section{Biochemical analyses}

For the biochemical analyses, $5 \mathrm{ml}$ of fasting venous blood was drawn by venipuncture from all participants. The blood samples were collected and centrifuged at $4,000 \times \mathrm{g}$ for $5 \mathrm{~min}$ to separate the plasma from the blood cells. Genomic DNA was extracted using the standard phenol-chloroform method. The DNA samples were stored at $-80^{\circ} \mathrm{C}$ for future analysis. For the analyses, the DNA was diluted to a $50-n g / \mu 1$ analysis. Fo. The plasma concentrations of glucose, total cholesterol (TC), triglyceride (TG), high-density lipoprotein cholesterol (HDL-C), low-density lipoprotein cholesterol (LDL-C), blood urea nitrogen (BUN), creatinine $(\mathrm{Cr})$, and uric acid (UA) were measured using standard methods at the Central Laboratory of the First Affiliated Hospital of Xinjiang Medical University as previously described [30-31].

\section{Genotyping the CYP19A1 gene}

We randomly selected 48 DNA samples with which to screen CYP19A1 gene mutation sequences. Mutation screening of 11 exons of the CYP19A1 gene was conducted at Genesky Biotechnologies Inc. (Shanghai, China). A total of 29 SNP loci were identified. After extensive review of the literature and information in the National Center for Biotechnology Information SNP database (http://www.ncbi.nlm.nih.gov/ SNP) and HuGE Navigator database (http://hugenavigator. net/), Haploview 4.2 software and the HapMap phase II database were used to obtain four tagged SNPs: rs2236722 (EXON2, missense, c.115T > C, p.Trp39Arg); rs2304463 (INTRON6, c.744-106T > G); rs4646 (3' UTR, c.*161T $>\mathrm{G}$ ); and rs4275794 (3' UTR, c.*1888A > G) for the Chinese population based on a minor allele frequency $(\mathrm{MAF}) \geq 0.05$ and linkage disequilibrium patterns with $\mathrm{r}^{2} \geq 0.8$ as a cutoff. We designated these SNPs as SNP1, SNP2, SNP3 and SNP4 in order of increasing distance from the $5^{\prime}$ end of the gene (Figure 4).

SNP genotyping was performed using the improved multiplex ligation detection reaction (iMLDR) technique (Genesky Biotechnologies Inc., Shanghai, China) as described by Dengming He et al. [32]. Randomly selected DNA samples from each genotype were sequenced to validate the genotyping using the ligation detection reaction method. The results of the ligation detection reaction method were consistent with the results of sequencing.

\section{Statistical analysis}

Statistical analyses were performed using SPSS 22.0 for Windows (SPSS Institute, Chicago, USA). Statistical significance was indicated by a $P$-value $<0.05$. All continuous variables (e.g., age, TC, TG, HDL-C, LDL-C, and body mass index (BMI)) are presented as the mean \pm standard deviation (SD), and the differences between the CAD and control groups were analyzed using independent-sample $t$-tests. All the variables (e.g., the frequencies of smoking, drinking, DM, and CYP19A1 genotypes) and the Hardy-Weinberg equilibrium were analyzed using the $\chi^{2}$ test or Fisher's exact test, as appropriate. Logistic regression analyses with effect ratios (odds ratio $[\mathrm{OR}]$ and $95 \%$ confidence interval $(\mathrm{CI})$ ) were used to assess the contributions of the major risk factors. A

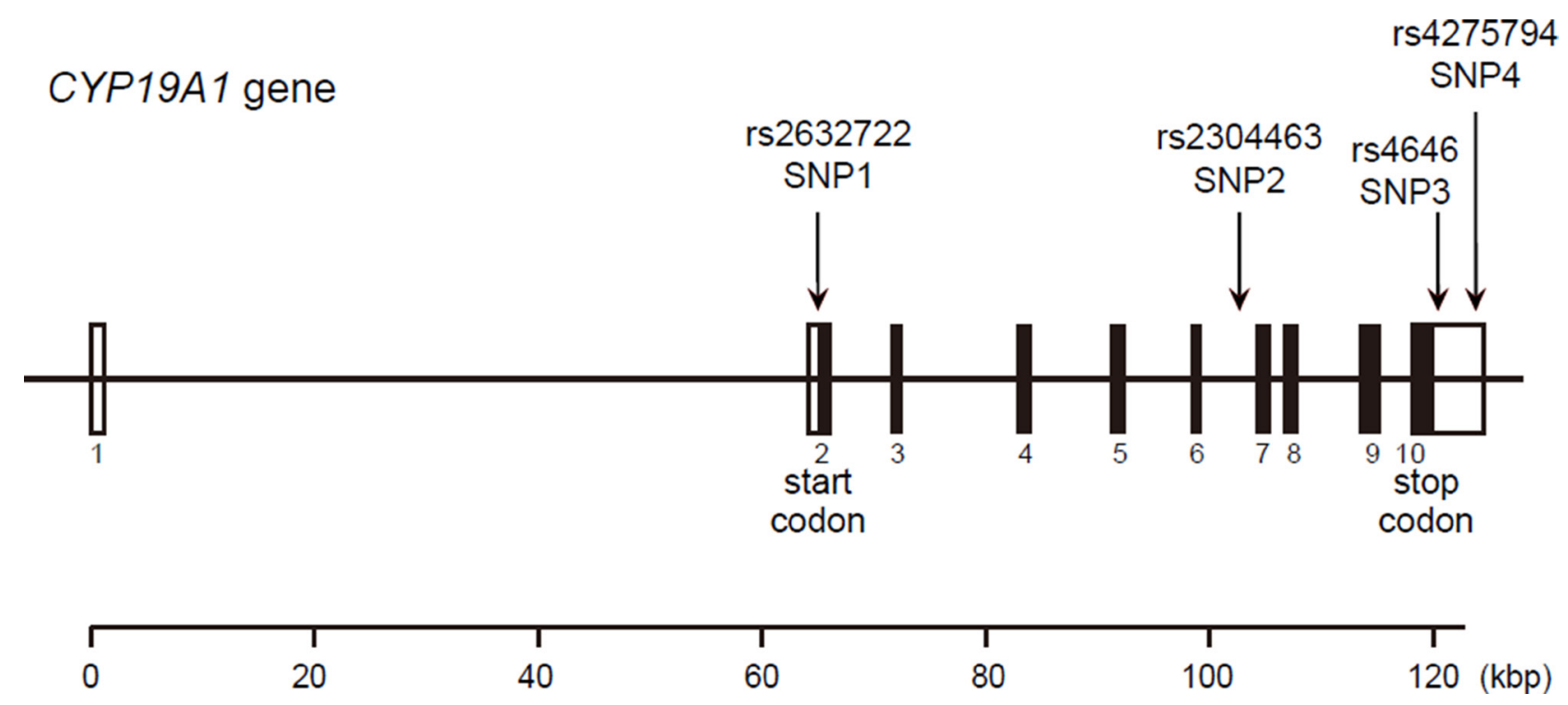

Figure 4: Structure of the human CYP19A1 gene. Boxes indicate exons, and lines indicate introns and intergenic regions. Filled boxes indicate coding regions. Arrows mark the locations of polymorphisms. 
general linear model (GLM) analysis was used to test for associations between SNP genotypes and sex hormone and aromatase levels after adjusting for confounding variables.

A two-degree-of-freedom likelihood ratio test for homogeneity of the effect of each SNP was performed. A $P$-value $\leq 0.05$ was considered statistically significant, and a value between 0.05 and 0.1 was considered marginally significant.

\section{CONCLUSIONS}

In summary, the results of the present study provide additional information concerning CYP19A1 polymorphisms and their associations with CAD, and to our knowledge, this study is the first to examine the association between tag SNPs in CYP19A1 and sex hormone levels in postmenopausal Xinjiang Chinese women. The results showed an association between estrone, testosterone, and aromatase levels in the SNP3 (rs4646) region in the 3' UTR of CYP19A1. This association may represent a potential susceptibility marker of hormone-dependent diseases in postmenopausal women. Additional studies and functional validation of these associations are needed to develop better hormone replacement therapies for the prevention and treatment of cardiovascular disease.

\section{ACKNOWLEDGMENTS AND FUNDING}

This work was supported financially by the National Natural Science Foundation of China (81560069, U1403221, 81260041), the Xinjiang Uygur Autonomous Region Key Laboratory Project (2015KL011) and the Xinjiang Uygur Autonomous Region Key R \& D projects (2016B03053).

\section{CONFLICTS OF INTEREST}

None.

\section{REFERENCES}

1. Turgeon JL, McDonnell DP, Martin KA, Wise PM. Hormone therapy: physiological complexity belies therapeutic simplicity. Science. 2004; 304:1269-1273.

2. Cury RC, Abbara S, Achenbach S, Agatston A, Berman DS, Budoff MJ, Dill KE, Jacobs JE, Maroules CD, Rubin GD, Rybicki FJ, Schoepf UJ, Shaw LJ, et al. Coronary Artery Disease-Reporting and Data System (CAD-RADS): An Expert Consensus Document of SCCT, ACR and NASCI: Endorsed by the ACC. JACC: Cardiovascular Imaging. 2016; 9:1099-1113.

3. Joakimsen O, Bønaa KH, Stensland-Bugge E, Jacobsen BK. Population-based study of age at menopause and ultrasound assessed carotid atherosclerosis: The Tromsø Study. Journal of clinical epidemiology. 2000; 53:525-530.
4. Brouchet L, Krust A, Dupont S, Chambon P, Bayard F, Arnal JF. Estradiol accelerates reendothelialization in mouse carotid artery through estrogen receptor- $\alpha$ but not estrogen receptor- $\beta$. Circulation. 2001; 103:423-428.

5. Aronow HD, Beckman JA. Parsing Atherosclerosis. Circulation. 2016; 134:438-440.

6. Desautels DN, Blanchette PS, Pritchard KI. Do aromatase inhibitors increase cardiovascular risk? Piecing together the evidence. European Journal of Cancer. 2016; 68:176-178.

7. Ziv-Gal A, Gallicchio L, Miller SR, Zacur HA, Flaws JA. A genetic polymorphism in the CYP19A1 gene and the risk of hypertension among midlife women. Maturitas. 2012; 71:70-75.

8. Peter I, Shearman AM, Zucker DR, Schmid CH, Demissie S, Cupples LA, Larson MG, Vasan RS, D'Agostino RB, Karas RH, Mendelsohn ME, Housman DE, Levy D. Variation in estrogen-related genes and cross-sectional and longitudinal blood pressure in the Framingham Heart Study. J Hypertens. 2005; 23:2193-2200.

9. Sebastian S, Bulun SE. A highly complex organization of the regulatory region of the human CYP19 (aromatase) gene revealed by the Human Genome Project. J Clin Endocrinol Metab. 2001; 86:4600-4602.

10. Akhtar M, Wright JN, Lee-Robichaud P. A review of mechanistic studies on aromatase (CYP19) and 17 $\alpha$-hydroxylase-17,20-lyase (CYP17). J Steroid Biochem Mol Biol. 2011; 125:2-12.

11. Armellini F, Zamboni M, Bosello O. Hormones and body composition in humans: clinical studies. Int J Obes Relat Metab Disord. 2000; 24:S18-S21.

12. Park IH, Lee YS, Lee KS, Kim SY, Hong SH, Jeong J, Lee H, Ro J, Nam BH. Single nucleotide polymorphisms of CYP19A1 predict clinical outcomes and adverse events associated with letrozole in patients with metastatic breast cancer. Cancer Chemother Pharmacol. 2011; 68:1263-1271.

13. Miron L, Negura L, Peptanariu D, Marinca M. Research on aromatase gene (CYP19A1) polymorphisms as a predictor of endocrine therapy effectiveness in breast cancer. Rev Med Chir Soc Med Nat Iasi. 2012; 116:997-1004.

14. Kopp TI, Jensen DM, Ravn-Haren G, Cohen A, Sommer HM, Dragsted LO, Tjonneland A, Hougaard DM, Vogel U. Alcohol-related breast cancer in postmenopausal women - effect of CYP19A1, PPARG and PPARGC1A polymorphisms on female sex-hormone levels and interaction with alcohol consumption and NSAID usage in a nested case-control study and a randomised controlled trial. BMC Cancer. 2016; 16:283.

15. Park SK, Andreotti G, Sakoda LC, Gao YT, Rashid A, Chen J, Chen BE, Rosenberg PS, Shen MC, Wang BS, Han TQ, Zhang $\mathrm{BH}$, Yeager $\mathrm{M}$, et al. Variants in hormone-related genes and the risk of biliary tract cancers and stones: a population-based study in China. Carcinogenesis. 2009; 30:606-14.

16. Hodis HN, Mack WJ, Shoupe D, Azen SP, Stanczyk FZ, Hwang-Levine J, Budoff MJ, Henderson VW. Methods and 
baseline cardiovascular data from the Early versus Late Intervention Trial with Estradiol testing the menopausal hormone timing hypothesis. Menopause (New York, NY). 2015; 22:391.

17. Savonitto S, Colombo D, Franco N, Misuraca L, Lenatti L, Romano IJ, Morici N, Lo Jacono E, Leuzzi C, Corrada E, Aranzulla TC, Petronio AS, Bellia G, et al. Age at Menopause and Extent of Coronary Artery Disease Among Postmenopausal Women with Acute Coronary Syndromes. The American Journal of Medicine. 2016; 129:1205-1212.

18. Zhu Y, Bian Z, Lu P, Karas RH, Bao L, Cox D, Hodgin J, Shaul PW, Thoren P, Smithies O, Gustafsson JA, Mendelsohn ME. Abnormal vascular function and hypertension in mice deficient in estrogen receptor $\beta$. Science. 2002; 295:505-508.

19. Haiman CA, Dossus L, Setiawan VW, Stram DO, Dunning AM, Thomas G, Thun MJ, Albanes D, Altshuler D, Ardanaz E, Boeing H, Buring J, Burtt N, et al. Genetic variation at the CYP19A1 locus predicts circulating estrogen levels but not breast cancer risk in postmenopausal women . Cancer research. 2007; 67:1893-7.

20. Cai H, Shu XO, Egan KM, Cai Q, Long JR, Gao YT, Zheng W. Association of genetic polymorphisms in CYP19A1 and blood levels of sex hormones among postmenopausal Chinese women. Pharmacogenetics and genomics. 2008; 18:657.

21. Kidokoro K, Ino K, Hirose K, Kajiyama H, Hosono S, Suzuki T, Kawase T, Hiraki A, Hamajima N, Tanaka H, Tajima K, Kikkawa F, Matsuo K. Association between CYP19A1 polymorphisms and sex hormones in postmenopausal Japanese women . Journal of human genetics. 2009; 54:78-85.

22. Dunning AM, Dowsett M, Healey CS, Tee L, Luben RN, Folkerd E, Novik KL, Kelemen L, Ogata S, Pharoah PD, Easton DF, Day NE, Ponder BA. Polymorphisms associated with circulating sex hormone levels in postmenopausal women. Journal of the National Cancer Institute. 2004; 96:936-945.

23. Paynter RA, Hankinson SE, Colditz GA, Kraft P, Hunter DJ, De Vivo I. CYP19 (aromatase) haplotypes and endometrial cancer risk. International journal of cancer. 2005; 116:267-274.

24. Shimodaira M, Nakayama T, Sato I, Sato N, Izawa N, Mizutani Y, Furuya K, Yamamoto T. Estrogen synthesis genes CYP19A1, HSD3B1, and HSD3B2 in hypertensive disorders of pregnancy. Endocrine. 2012; 42:700-707.

25. Kloner RA, Carson C 3rd, Dobs A, Kopecky S, Mohler ER 3rd. Testosterone and cardiovascular disease. Journal of the American College of Cardiology. 2016; 67: 545-557.

26. Rosenfield R L, Ehrmann D A. The Pathogenesis of Polycystic Ovary Syndrome (PCOS): The Hypothesis of PCOS as Functional Ovarian Hyperandrogenism Revisited. Endocrine Reviews. 2016; 37:467-520.

27. Orio F, Muscogiuri G, Nese C, Palomba S, Savastano S, Tafuri D, Colarieti G, La Sala G, Colao A, Yildiz BO. Obesity, type 2 diabetes mellitus and cardiovascular disease risk: an uptodate in the management of polycystic ovary syndrome. European Journal of Obstetrics \& Gynecology and Reproductive Biology. 2016; 207:214-219.

28. Biegon A, Kim SW, Logan J, Hooker JM, Muench L, Fowler JS. Nicotine blocks brain estrogen synthase (aromatase): in vivo positron emission tomography studies in female baboons. Biological psychiatry. 2010; 67:774-777.

29. American Diabetes Association. 2. Classification and diagnosis of diabetes. Diabetes Care. 2016; 39:S13-S22.

30. Abudoukelimu M, Fu ZY, Xiang Y, Ma YT, Zhu Q, Abudu M, Adi D, Yang YN, Li XM, Xie X, Liu F, Chen BD. Genetic variants of numb gene were associated with elevated total cholesterol level and low density lipoprotein cholesterol level in Chinese subjects, in Xinjiang, China. Diagnostic pathology. 2015; 10:141.

31. Fu YZ, Wang B, Ma TY, Huang D, Liu F, Dong LC, Wang T, Meng JY. A Novel Polymorphism of the CYP19 Gene is Associated with Essential Hypertension in China. Clinical laboratory. 2015; 62:195-202.

32. He D, Tao S, Guo S, Li M, Wu J, Huang H, Guo X, Yan G, Zhu P, Wang Y. Interaction of TLR-IFN and HLA polymorphisms on susceptibility of chronic HBV infection in Southwest Han Chinese. Liver Int. 2015; 35:1941-9. 